\title{
Coordenação pedagógica A dialética entre o legal e o real
}

\section{Shirlei de Souza CorrêA* Verônica Gesser **}

RESUMO: O trabalho pedagógico desenvolvido no interior das escolas foi historicamente afetado. Observou-se com esta pesquisa que, na rede pública estadual catarinense, os coordenadores intitulados assistentes técnico-pedagógicos estabelecem uma relação de dependência entre as ações cotidianas e as atribuições do documento norteador, sobretudo, por se dividirem entre a teoria e a prática, baseados no trabalho fragmentado, não conseguindo, assim, realizar um trabalho articulado com os interesses do coletivo.

Palavras chave: Coordenação pedagógica. Trabalho coletivo. Atribuições profissionais.

\section{Pedagogical Coordination}

The tension between the legal and the real

\begin{abstract}
The pedagogical work developed within schools has been historically compromised. This research observed that the network of public state education in Santa Caterina, through the entitled coordinators technical pedagogical assistants, established a relationship of dependency between daily actions and the assignments from the guiding documents, especially discriminating between theory and practice. As this was based on fragmented work it was not possible to construct an articulated comprehensive approach in the collective interest.
\end{abstract}

* Doutoranda em Educação. Docente no Curso de Pedagogia da Universidade Federal de Santa Catarina (UFSC). Itajaí/SC - Brasil. E-mail: <shirleiscorrea@hotmail.com>.

* Doutora em Educação. Atualmente é vice-coordenadora, professora e pesquisadora da Universidade do Vale do Itajaí (Univali) no Programa de Pós-Graduação (PPGE) Stricto-Sensu em Educação (Mestrado e Doutorado) no Núcleo das Licenciaturas (presencial e Ead). Itajai/SC - Brasil. E-mail: <gesserv@univali.br>. 
Key words: Pedagogical coordination. Collective work. Professional attributions.

\section{Coordinación pedagógica \\ La dialéctica entre lo legal y lo real}

RESUMEN: El trabajo pedagógico desarrollado dentro de las escuelas se ha afectado históricamente. Con este estudio se observa que, en la red pública del estado de Santa Catarina, los coordinadores llamados asistentes técnicos/pedagógicos establecen una relación de dependencia entre las acciones cotidianas y las atribuciones del documento de orientación, sobre todo por dividirse entre la teoría y la práctica, basados en el trabajo segmentado, sin lograr con ello la realización de un trabajo articulado con los intereses colectivos.

Palabras clave: Coordinación pedagógica Trabajo colectivo. Atribuciones profesionales.

\section{Coordination pédagogique}

La dialectique entre le légal et le réel

RÉSUMÉ: Le travail pédagogique réalisé dans les écoles a toujours été historiquement touché. On remarque dans cette recherche que, dans le réseau public de l'état de Santa Catarina, les coordinateurs appelés assistants technico-pédagogiques instaurent une relation de dépendance entre les actions quotidiennes et les tâches attribuées par le document d'orientation, lesquelles se divisent entre la théorie et la pratique, ce qui donne lieu à une fragmentation du travail et les empêchent de réaliser un travail articulé avec les intérêts de la collectivité.

Mots-clés: Coordination pédagogique. Travail collectif. Tâches professionnelles. 


\section{Primeiras palavras}

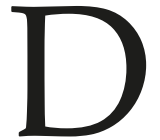

urante séculos a educação brasileira viu-se cercada pela necessidade de controlar o processo educativo, as ações desenvolvidas no interior das escolas e os responsáveis por estas ações. Esse controle era por vezes influenciado por questões históricas e culturais, outras por questões políticas. As ações que emergiam dessa prática controladora eram pautadas na vigilância e na punição e ganhavam forma através das ações de profissionais, como os inspetores escolares, treinados e responsabilizados pela função. O caráter rígido e autoritário, resultado da prática controladora, tinha a finalidade de avaliar o andamento do estabelecimento escolar e manter o controle das práticas escolares, desde a atuação do professor até o nível de desenvolvimento dos alunos.

Com o contexto democrático, instituído a partir da década de 1980, algumas das mais consideráveis mudanças na educação no Brasil aconteceram, entre elas a instituição de políticas públicas, a criação e adequação de legislações, o investimento em formação inicial e continuada entre outros. Elas propiciaram o desencadeamento de conceitos e práticas de gestão e de participação da comunidade nas decisões da escola. E foi nesse contexto que a atuação do profissional que praticava a ação controladora perdeu espaço para aquele que, a partir dos movimentos democráticos, passaria a atuar de forma articuladora, em conjunto com a comunidade escolar.

Este profissional, intitulado coordenador pedagógico, recebeu destaque na principal legislação educacional do País, a Lei de Diretrizes e Bases de número 9394, de 1996, que reconhece as mudanças na educação e sugere a ressignificação da prática exercida por este profissional no interior das escolas públicas e privadas.

A partir dos conceitos que tratam da ressignificação da função, este texto objetiva apresentar os achados de uma pesquisa qualitativa ${ }^{1}$, que teve como principal intenção pesquisar a relação estabelecida pelo coordenador pedagógico, entre os documentos legais e a prática realizada cotidianamente no interior das escolas públicas vinculadas à rede estadual catarinense.

O texto apresenta a trajetória da coordenação pedagógica no Brasil, com especial destaque ao estado catarinense e a este profissional que é intitulado assistente técnico-pedagógico. Em seguida, trata da atuação desse profissional, para, finalmente, apresentar e discutir alguns achados da pesquisa.

\section{A coordenação pedagógica: o que sabemos}

A escola, marcada historicamente por mudanças, tornou-se complexa, múltipla e detentora de contextos individuais. A estrutura e a organização do trabalho na escola, a 
partir da ótica de uma equipe pedagógica ou equipe gestora, passou a ser considerada uma das importantes mudanças no cenário educativo.

O caráter rígido e autoritário, com a finalidade de avaliar o andamento do estabelecimento escolar, a prática do professor até o nível de desenvolvimento dos alunos marcou um período de fiscalização em todos os ambientes da escola, preconizado, segundo Saviani (2003), na educação jesuítica.

Esta concepção autoritária e reguladora manteve-se atenta, sobretudo, ao sistema educacional da época.

A inspeção escolar ocupou um lugar de destaque na ação de reorganizar o ensino. Os inspetores incorporaram padrões de desempenho de eficiência para avaliar o trabalho do diretor, do professor, dos funcionários administrativos e dos alunos, o que revela uma racionalidade técnica e um controle ostensivo, que, em certa medida, fornecia indicações de como deveria se consolidar o sistema de ensino. (BARCELOS, 2014, p. 91).

A partir da década de 1960, influenciados pelos acordos com o MEC/Usaid, o Brasil vivenciou a necessidade de legitimar a educação frente às concepções modernas impostas à nacionalidade brasileira, apostando na racionalidade capitalista e na preparação de mão-de-obra técnica e qualificada. A Reforma Universitária propiciou a formação dos especialistas em assuntos educacionais no curso de Pedagogia, sendo que estes profissionais recebiam a titulação de bacharelados ou licenciados.

A atuação destes especialistas nas escolas de todo o País teve seu auge durante as décadas de 1980 e 1990. Seu declínio, a partir da década de 1990, foi marcado pelo desencadeamento de movimentos de democratização da educação brasileira. Pinto (2011) afirma que havia duras críticas ao pedagogo egresso das diferentes habilitações, que tinha uma visão fragmentada do trabalho desenvolvido nas escolas.

Assim, com as reformas educacionais em alta, e o encerramento dos modelos curriculares centrados na formação das habilitações, a prática fragmentada evoluiu para a condensação das habilitações em uma função: a coordenação pedagógica. A coordenação pedagógica, tema recorrente em diversos estudos, não apresenta uma linearidade histórica, pois ela vem se constituindo, também, a partir de características herdadas dos especialistas em educação, nas funções de orientador, supervisor e administrador escolar.

Todavia, é possível perceber que muitas características atribuídas a este profissional através de estudos recentes propõem a formulação de sua identidade. Atitudes de articulação pedagógica (PLACCO, 2011), trabalho coletivo (GEGLIO, 2011) e a prática da formação continuada de professores são atribuídos ao coordenador pedagógico atuante nas escolas. Nestes moldes, a função de coordenação pedagógica se organiza e se converte a partir de pressupostos teóricos voltados, sobretudo, à articulação do trabalho coletivo, com foco na atuação dos professores, bem como no processo ensino-aprendizagem. 
No estado de Santa Catarina, a coordenação pedagógica segue uma trajetória parecida com a que se conhece no resto do País, embora apresente algumas características próprias. Uma delas diz respeito à nomenclatura: no estado catarinense o coordenador pedagógico é intitulado assistente técnico-pedagógico.

A nomenclatura de assistente técnico-pedagógico, embora pouco utilizada no País e dificilmente evidenciada em pesquisas bibliográficas, nos aponta uma infinidade de possibilidades que circundam o fazer cotidiano deste profissional, muito próximo à prática exercida pelo coordenador pedagógico.

Num exercício de busca por pesquisas que tratassem da coordenação pedagógica, foram encontradas diversas nomenclaturas ou conjunto de palavras e/ou expressões que traziam expressiva significação ao trabalho desenvolvido pelo pedagogo ou correspondente, inclusive, do assistente técnico-pedagógico, no acompanhamento das atividades desenvolvidas pela comunidade escolar.

Educador-profissional, identificado como pedagogo escolar por Pinto (2011), coordenador pedagógico utilizado por Pimenta (s/d) e por Placco (2010), professor coordenador pedagógico por Barreira (2006), entre tantos outros termos encontrados na literatura, traduzem as particularidades da nomenclatura dos profissionais que desenvolvem o trabalho no âmbito coletivo no interior das escolas.

Diante deste fato, Pinto (2011) descreve certa desconexão quanto à nomenclatura utilizada no no País para denominar os executores do trabalho realizado na escola:

essa variação na nomenclatura da função, encontrada em diferentes estados e municípios, é ainda mais confusa por corresponder, em muitos lugares, às funções assumidas pelo pedagogo que atua fora das escolas em diferentes instâncias do sistema estadual ou municipal das secretarias da educação. (PINTO, 2011, p. 80)

Baseado nos estudos desse autor, cabe denominar, neste estudo, os assistentes técnico-pedagógicos como coordenadores pedagógicos, haja vista haver total relação entre suas funções.

Outra característica sobre o cargo de assistente técnico-pedagógico, é que este foi um cargo criado com a finalidade de atender uma demanda especificamente técnica nos órgãos da Secretaria de Educação do Estado. Entretanto, ao longo de décadas, o cargo sofreu mudanças em sua estrutura. A maior e mais importante deve-se ao fato de que os profissionais que atuavam nesse cargo passaram a atender, de acordo com legislações específicas, as questões técnicas e pedagógicas nas escolas onde passaram a atuar. O cargo passou a representar, para o estado de Santa Catarina, a aglutinação dos orientadores educacionais, dos administradores e dos supervisores escolares.

Com características históricas semelhantes à coordenação pedagógica, a função do assistente técnico-pedagógico, que, assim como a coordenação pedagógica, foi fruto de um movimento de democratização da educação, em substituição aos especialistas 
em assuntos educacionais, a partir de 2005, passando então a integrar a equipe pedagógica das escolas.

A trajetória profissional do assistente técnico-pedagógico nas escolas vinculadas a rede estadual, de acordo com Corrêa (2013) sinaliza que não somente seu início foi conturbado, como também sua prática ao longo desses anos. Inseridos numa dinâmica baseada no trabalho fragmentado, com divisão de tarefas, eles se adequaram à realidade das escolas e organizaram suas ações, a partir de uma lista de atribuições composta por 20 questões, que orientam e organizam sua prática profissional no interior das escolas.

\section{A atuação do coordenador pedagógico: o que percebemos}

Para o desenvolvimento desta investigação, que teve como objetivo pesquisar a relação estabelecida pelo assistente técnico-pedagógico, também chamando neste estudo de coordenador pedagógico entre os documentos legais e a prática realizada cotidianamente no interior das escolas, foi preciso, incialmente, conhecer a prática deste profissional.

Quando questionados durante a coleta de dados sobre as atividades desenvolvidas durante o ano letivo, todos os participantes afirmaram, durante as entrevistas, ser impossível seguir o planejamento realizado, em função das necessidades cotidianas, o que foi ratificado durante a discussão no Grupo Focal. A fala do ATP2 quando questionado sobre seu trabalho confirma: "Nem sempre dá pra fazer o que foi pensado ou planejado, muitas vezes não dá pra fazer por causa das emergências que vão surgindo."(GF).

Atuar profissionalmente num cenário assim pressupõe pouca organização diante das questões técnicas e burocráticas, onde fazer escolhas é o caminho mais fácil para administrar a grande demanda de atividades. Para Vasconcellos (2006), para transformar a realidade e lhe dar uma direção escolhida necessariamente deve haver planejamento. Gesser (2011, p. 24) contribui: “[...] é o planejamento educacional que indica as metas e os objetivos para a educação a partir de um conjunto de valores éticos, políticos, sociais, culturais, entre outros."

No que compreende a organização da prática diária, recorremos a Placco (2010), que, na tentativa de categorizar um estudo acerca do coordenador pedagógico e o confronto com o cotidiano escolar, deu importante destaque a temas como importâncias, rotinas, urgências e pausas, para que pudessem consolidar a prática destes profissionais. Para a autora,

As atividades do par IMPORTÂNCIA-ROTINA são planejáveis previamente, constituindo-se em arcabouço da organização escolar. URGÊNCIA-PAUSA são atividades decorrentes da dinâmica da escola e de necessidades emergentes do cotidiano. (PLACCO, 2010, p. 49), 
A partir dessa teoria, a autora constatou que em muitos casos os coordenadores pedagógicos "elegem prioridades" diante das exigências diárias ou das urgências surgidas, o que pode, em muitos casos, dificultar a realização de atividades previamente planejadas. E no trabalho desenvolvido pelos assistentes técnico-pedagógicos existe rotina ou as emergências ditam o seu ritmo?

Muita semelhança pode ser encontrada na fala dos assistentes técnico-pedagógicos à teoria de Placco (2010). Quando a questão do trabalho cotidiano foi direcionada durante o Grupo Focal, gerando discussões, muitas contribuições denunciaram a falta de rotina e de organização profissional. A fala do ATP 1 nos aponta essa realidade: "Um dia tu estás no administrativo, outro dia precisa no pedagógico, outro dia é outra necessidade e assim vai...e o planejamento? Nessas horas nem dá tempo de pensar no planejamento, é uma correria só." (E)

É possível perceber que a falta de planejamento e organicidade por parte dos assistentes técnico-pedagógicos deixa o profissional em sobreposição ao ambiente escolar, pois ele atua em toda a escola, atendendo as emergências a que Placco (2010) se referiu. Do mesmo modo, o ATP2 relata a multiplicidade de funções que realiza, atendendo a demanda e a necessidade. Por fim, ressaltamos a fala do ATP3, que realiza consertos e reparos na estrutura física da escola: "Sem falar que se quebra uma fechadura, quem conserta sou eu, se cai uma cortina, quem conserta sou eu, se estraga uma porta, quem vai lá arrumar sou eu”. (E).

Diante disso, alguns questionamentos podem ser feitos: Essa realidade se refere à falta de conhecimento do profissional quanto à sua atuação? Ou as exigências do cotidiano escolar se sobressaem às ações planejadas?

Segundo Pinto (2011), muitas vezes o coordenador pedagógico atende as necessidades advindas das condições inadequadas de trabalho e deixa de atuar no âmbito das atividades pedagógicas. Por falta de conhecimento das próprias funções, por falta de orientações e conhecimentos sobre a equipe pedagógica, o fato é que na prática dos assistentes técnico-pedagógicos, suas ações estavam voltadas às questões emergenciais no cotidiano escolar.

Soares (2011) em sua pesquisa com coordenadores pedagógicos observou que muitas das ações desenvolvidas pelos coordenadores atendiam a questões burocráticas ou partiam da exigência dos gestores, deixando para segundo plano as questões pedagógicas. $\mathrm{O}$ autor segue apontando a falta de sincronia entre os profissionais atuantes na escola e atribui ao gestor grande responsabilidade em organizar este trabalho. Para ele,

Não se trata de individualizar ou integrar todas as ações, mas de o gestor gerenciar as ações de toda sua equipe, mediando o processo e delegando a função ao responsável de fato pela execução das atividades, o que não impede uma participação de todos na realização do que foi solicitado. Talvez seja necessário que os gestores compreendam que não se trata de segmentar o trabalho dos profissionais da escola, mas gerenciar com base nas atribuições e competências de sua equipe, delegando ao profissional que atuará de forma consciente de suas funções e com base nas experiências anteriores, o que contribuirá para a resolução do problema com maior eficácia. (SOARES, 2011, p. 51). 
No bojo dessa discussão, Almeida (2010), usando de uma metáfora, afirma que os coordenadores pedagógicos estão constantemente em um labirinto de escolhas. Estar à disposição das emergências ou das necessidades (e até dos interesses) da escola, dos gestores, dos professores e dos alunos, segundo a autora, é uma das tarefas mais difíceis para o coordenador. As falas dos assistentes técnico-pedagógicos refletiram igual dificuldade.

Do mesmo modo, seu contrário apresenta um grau maior ainda de dificuldades. Desafiar as exigências momentâneas e impor-se diante das situações, por fim, tomando decisões que visam o bom andamento da escola, exige, sobretudo, planejamento. "É preciso ter coragem para fazer escolhas, definir metas, aproveitar brechas, criar espaços, fazer parcerias." (ALMEIDA, 2010, p. 45). Estar num labirinto de escolhas como dito pela mesma autora é, também, uma questão de escolha para o coordenador pedagógico. As atitudes desse profissional diante da demanda no cotidiano da escola exige certa imposição, o que propõe maior direcionamento e fidelidade às práticas planejadas e, à necessidade de planejá-las.

Não se trata de levantar a bandeira do individualismo, mas sim a ideia de que cada profissional possui atribuições específicas que se relacionam e se complementam, bem como reconhecer a existência de atribuições conjuntas em prol de melhorias na aprendizagem dos discentes. (SOARES, 2011, p. 49)

Ainda no que tange às questões emergenciais como um desafio à prática do coordenador, surgem, nos estudos de Almeida (2010), metáforas, que imprimem sua prática tarefeira e inconstante. Apagador de incêndio e coringa são algumas das mais utilizadas em estudos apresentados sobre o tema. Durante a pesquisa com os assistentes técnico-pedagógicos sobre suas atribuições, comumente surgiram metáforas a respeito do exercício profissional. De acordo com Almeida (2010), alguns coordenadores se utilizam das metáforas por conta da complexidade das funções ou mesmo pela falta de delimitação. A autora acrescenta, ainda, que a metáfora é uma forma de organizar diferentes aspectos da própria experiência.

\section{$O$ real $X$ o legal: o que descobrimos}

Ao tratar da prática do assistente técnico-pedagógico, pouco organizada e baseada nas ações emergenciais, voltamo-nos às atribuições legais, expostas na lista de atribuições, documento norteador de seu trabalho, sobretudo na relação estabelecida entre as atribuições legais e as reais, desenvolvidas pelo profissional no cotidiano escolar. 
Quando questionados sobre a lista de atribuições durante o Grupo Focal, os participantes fizeram menção negativa ao formato do documento, principalmente porque este nunca foi analisado, discutido e repensado no decorrer dos anos. Todavia, apesar das críticas, afirmaram segui-lo, haja vista ser o único documento orientador da prática do assistente técnico-pedagógico. No olhar do profissional "a lista é muito vaga... não é clara e não define se é um serviço mais voltado pro administrativo ou pro pedagógico." (E) (ATP01)

Alguns participantes se queixaram da falta de objetividade de muitos itens da lista. O ATP5 destacou o que seria, segundo ele, uma incoerência: o item 7- "prestar auxílio no desenvolvimento de atividades relativas à assistência técnica aos segmentos envolvidos diretamente com o processo ensino-aprendizagem;". E o quinto item que se refere a: "auxiliar na coleta e organização de informações, dados estatísticos da escola e documentação".

Para ele, a incoerência se apresenta no fato das atribuições tratarem de questões pedagógicas e técnicas, respectivamente. No entanto, as ações, embora com diferentes estratégias, canalizam-se à mesma finalidade: ao processo ensino-aprendizagem. Seria possível planejar e/ou executar as ações voltadas ao processo de ensino-aprendizagem, sem informações e/ou diagnóstico da comunidade escolar?

Pinto (2011), em sua teoria, afirma que em muitos casos os coordenadores pedagógicos são tomados por funções burocráticas, mas reconhecem que o ponto principal de seu trabalho está "no movimento inter-relacional dessas diferentes condições". Exatamente o sincronismo de Soares (2011) posto em prática. Para Aguiar (2010, p. 142)

A atribuição do coordenador pedagógico se amplia para o trabalho com professores, pais e alunos, em busca de estabelecer parcerias para o sucesso deste trabalho que, todavia, não ocorre isoladamente, mas em articulação com o gestor e com o apoio de outros profissionais.

A dificuldade dos assistentes técnico-pedagógicos em realizar um trabalho voltado às questões da escola, de forma articulada, foi também diagnosticada pela atividade realizada ao fim do encontro no Grupo Focal. A atividade proposta era que os sujeitos descrevessem em papéis algumas das principais atividades desenvolvidas por eles no cotidiano escolar, para, em seguida, analisarem a lista de atribuições e classificassem as atividades descritas segundo as alternativas: Relação total, Relação parcial e Relação nula.

O exercício resultou na Tabela 01, transcrita tal e qual, possibilitando uma análise reflexiva acerca das principais atividades no cotidiano escolar e a relação estabelecida com aquelas apresentadas na lista de atribuições: 
Tabela 1 - Relação entre as atividades reais e as legais

\begin{tabular}{|l|l|l|}
\hline Relação total & Relação parcial & Relação nula \\
\hline $\begin{array}{l}\text { Organizar o PPP em } \\
\text { conjunto com a equipe. }\end{array}$ & Atendimento a professores. & $\begin{array}{l}\text { Montar processo de } \\
\text { alunos com problemas de } \\
\text { aprendizagem. }\end{array}$ \\
\hline $\begin{array}{l}\text { Participar dos conselhos de } \\
\text { classe. }\end{array}$ & $\begin{array}{l}\text { Acompanhar planejamento } \\
\text { dos professores. }\end{array}$ & $\begin{array}{l}\text { Cuidar, conversar, advertir, } \\
\text { orientar os alunos. }\end{array}$ \\
\hline $\begin{array}{l}\text { Participar na elaboração do } \\
\text { PPP. }\end{array}$ & $\begin{array}{l}\text { Atendimento de alunos no } \\
\text { que se refere à questão de } \\
\text { indisciplina. }\end{array}$ & $\begin{array}{l}\text { Registro de merenda } \\
\text { terceirizada no sistema. }\end{array}$ \\
\hline $\begin{array}{l}\text { Fazer o censo escolar. } \\
\text { Atuar na secretaria no } \\
\text { atendimento ao público, } \\
\text { telefone, histórico escolar, } \\
\text { documentação de alunos e } \\
\text { outros. }\end{array}$ & $\begin{array}{l}\text { Ir pra sala de aula quando } \\
\text { falta professor. }\end{array}$ \\
\hline $\begin{array}{l}\text { Organização de projetos } \\
\text { pedagógicos. }\end{array}$ & $\begin{array}{l}\text { Participação na elaboração } \\
\text { do PPP, supervisão } \\
\text { de diários de classe e } \\
\text { planejamento do professor. }\end{array}$ & \begin{tabular}{l} 
Substituir professor. \\
\hline $\begin{array}{l}\text { Auxiliar o professor na } \\
\text { elaboração do planejamento. }\end{array}$
\end{tabular} \\
\hline $\begin{array}{l}\text { Organizar formação } \\
\text { continuada para professores. }\end{array}$ & \begin{tabular}{l} 
Consertar portas e cortinas. \\
\hline
\end{tabular} & $\begin{array}{l}\text { Substituir a direção da escola } \\
\text { quando não se encontra. }\end{array}$ \\
\hline
\end{tabular}

Fonte: Elaborado pela pesquisadora, 2013.

Ao analisar a segunda opção oferecida durante a dinâmica, a Relação parcial, algumas questões expostas pelos participantes se mostraram contraditórias. Como o coordenador pedagógico pode organizar seu trabalho sem estar voltado às principais figuras de uma escola: alunos e professores? Após este questionamento, cabe a contribuição de Souza, (2011, p. 95), quando afirma que "o trabalho do coordenador pedagógico se concretiza a partir de uma prática que assume características de organização, orientação e harmonização com toda a comunidade escolar." (Grifos nossos).

Realizar um trabalho voltado a toda a comunidade escolar, como citado por Souza (2011), pressupõe uma prática voltada às questões intrínsecas ao cotidiano escolar. As informações coletadas durante essa pesquisa nos permitem perceber que os assistentes técnico-pedagógicos não têm clareza da sua real função, pois a lista de atribuições traz, no sétimo item, uma das atribuições relacionada ao auxílio de atividades de assistência técnica aos segmentos envolvidos diretamente com o processo ensino-aprendizagem. Assim sendo, este item apresenta total relação com as atividades citadas pelos participantes.

Do mesmo modo, ao classificar as principais ações desenvolvidas por eles como Relação parcial, não perceberam que todas as ações listadas têm total relação com as 
atribuições expostas no documento. A falta de clareza quanto às funções é evidenciada novamente na última opção, que tem correspondência com a Relação nula. $\mathrm{O}$ trabalho relacionado a alunos e professores é classificado pelos sujeitos ouvidos como não inerente à prática do assistente técnico-pedagógico. Seria, então, possível conceber que um coordenador pedagógico não se envolva em questões de indisciplina de alunos? Ou no acompanhamento do planejamento de professores?

Para Pinto (2011), a atuação do coordenador junto ao professor e ao aluno proporciona viabilidade e vitalidade ao trabalho planejado. Ele continua afirmando que o coordenador deve trabalhar com os professores e não somente para os professores, reafirmando a lógica do trabalho coletivo. A função de coordenação pedagógica se organiza a partir de pressupostos teóricos voltados à articulação do trabalho coletivo, com foco na atuação dos professores, bem como no processo ensino-aprendizagem. Para Soares:

[...] o coordenador pedagógico reconhece que está em constante mudança, tornando-se parceiro político-pedagógico do professor. Em parceria com o professor, o CP contribui para integração de novos conteúdos, para a constante revisão do currículo, a organização do trabalho pedagógico da escola e das metodologias afixadas na transmissão do conhecimento, dando ao professor a oportunidade de um movimento de atualização constante, no qual os saberes e os conhecimentos confrontam-se desencadeando a construção de novos conceitos. (SOARES, 2011, p. 116)

Ainda como Relações nulas foram classificadas ações como substituição de professores e de direção de escola. Apesar dessas atribuições não estarem explícitas no documento, podemos considerá-las inerentes ao trabalho do coordenador, (desde que não se transforme em prática recorrente), pois para Placco e Souza (2010) e Pinto (2011) o coordenador pedagógico é parte constituinte da equipe diretiva da escola, devendo atuar numa prática coletiva.

A lista de atribuições, documento norteador para o trabalho dos assistentes técnico-pedagógicos, explicita a necessidade de um trabalho que interligue os diferentes setores da escola. Os itens 01, 02, 05, 10,12, 13 e 17 estão direcionados ao trabalho técnico, e se complementam com os itens $6,7,8,9,14$ e 15, que se referem às questões pedagógicas. Para Pinto (2011), as questões técnicas e pedagógicas se complementam na busca pelo sucesso da prática pedagógica, garantindo, assim, a qualidade de ensino.

Para Geglio (2010, p. 117), o coordenador pedagógico vem para atuar no "papel de mediador, de interlocutor, de orientador, de propositor, de investigador do grupo e com o grupo." Deste modo é possível afirmar que a coordenação pedagógica surge para unificar o trabalho no ambiente escolar, sendo que, a partir de movimentos democráticos, o profissional deixou de supervisionar e passou a fazer parte do grupo, como autor da própria história, atuando em todos os campos da escola, desde a organização técnica à pedagógica. 
Já a Relação total entre as atividades desenvolvidas e aquelas estabelecidas na lista de atribuições foi organizada pelos participantes sem grandes dificuldades. Todas as atividades descritas pelos assistentes técnico-pedagógicos apresentam relação com a lista de atribuições do profissional, o que pressupõe Relação total entre as funções realizadas e a lista de atribuições.

Diante do exposto é possível perceber que todas as atividades listadas como as mais comuns pelos assistentes técnico-pedagógicos condizem com a prática realizada pelo coordenador pedagógico, como demonstram estudos que fazem referência à temática.

Outra questão que merece destaque é a presença dos itens 8, 14 e 20 na lista de atribuições que orienta o trabalho do assistente técnico-pedagógico. São eles: 8- "desenvolver outras atividades afins ao órgão e a sua área de atuação"; 14- "comprometer-se com atendimento às reais necessidades escolares"; 20- "executar outras atividades de acordo com as necessidades da escola".

Há muita semelhança na descrição e na finalidade: atender a demanda da escola de modo generalizado. No entanto, essa semelhança não garante segurança aos assistentes tescola são essas? Que atividades afins eu tenho que desenvolver? Esses questionamentos transparecem a angústia de alguns assistentes técnico-pedagógicos, que se sentem atrelados à lista de atribuições e, mesmo sem a compreender, a tomam como modelo de atuação.

É certo que há dúvidas por parte dos assistentes técnico-pedagógicos em relação às suas atribuições legais. No entanto, mesmo sem concordar, ou sem aceitar o conteúdo do documento, o fatoé que os profissionais o tomaram como prescrição para desenvolver seu trabalho.

\section{Palavras finais}

Este texto, resultado das discussões sobre coordenação pedagógica, em especial ao assistente écnico-pedagógico, está fundamentado numa concepção de escola que sofreu ao longo dos tempos significativas mudanças em sua estrutura. De âmbito social, cultural e histórica, as mudanças influenciaram diretamente a organização do trabalho realizado no seu interior.

Os profissionais atuantes na função de assistente técnico-pedagógico, ao aliarem seus saberes práticos e experienciais, construíram, a seu modo, alguns com mais facilidade, outros com menos, diferentes saberes profissionais acerca da realidade escolar (CORRÊA, 2013). Essa construção da prática profissional exigiu uma parcela de improvisação e de adaptação frente à demanda apresentada.

A escuta dos sujeitos revelou que, na chegada destes profissionais à escola, o que lhes serviu de base para realização do seu trabalho e na organização de tais saberes foi uma lista de atribuições, um documento norteador, configurado a partir da prática do coordenador pedagógico. 
No entanto, percebemos que a lista de atribuições não serviu apenas como um norte, como parâmetro para o trabalho do assistente técnico-pedagógico. Pelo contrário: serviu para sistematizar o trabalho desenvolvido por estes profissionais nas escolas, pois as atribuições foram utilizadas como manual do que, como e quando realizar determinadas tarefas. Seria então mais confortável para o assistente técnico-pedagógico organizar suas ações a partir de um documento ou vivenciar a dinamicidade da escola e assumir seu real papel? Mas que real papel é este? Os profissionais têm conhecimento de sua função?

Críticas por parte dos assistentes técnico-pedagógicos ao conteúdo desse documento se fizeram presentes durante a coleta de dados. No entanto, o mesmo documento foi utilizado como parâmetro para a realização do trabalho, surgindo assim uma relação de submissão por parte do profissional ao documento legal.

Observamos, ainda, uma interpretação prescritiva do conteúdo desse documento por parte do assistente técnico-pedagógico, resultando numa relação de dependência por moldes de atuação no cenário educativo. A necessidade por direcionamentos é resultado de uma vivência baseada em modelos, que, de acordo com os relatos, foram vivenciados pela maioria dos participantes.

Ao discutir a relação estabelecida entre os documentos legais e a prática realizada cotidianamente no interior das escolas públicas vinculadas à rede estadual catarinense, percebemos que os assistentes técnico-pedagógicos enfrentam muitas dúvidas sobre a organização do seu trabalho. E, assim como o coordenador pedagógico, encontra obstáculos para realizar suas atividades, pois é atropelado pelas tarefas urgentes e necessidades oriundas do cotidiano escolar.

Enquanto figura nova e sem tradição na estrutura institucional, tem suas funções ainda mal compreendidas e mal-delimitadas, com poucos parceiros e frequentemente sem nenhum apoio na unidade escolar, precisa vencer seus medos, suas inseguranças, seu isolamento para conquistar seu espaço. (GARRIDO, 2009, p. 11)

No bojo da discussão, profissionais com pouca tradição nas escolas vinculadas à rede estadual de Santa Catarina, os assistentes técnico-pedagógicos, estabeleceram uma relação de dependência com a lista de atribuições, tomando-a como um documento rígido, permeado de imposições, capaz de delimitar suas ações no cotidiano escolar.

O fato é que a lista de atribuições não tem esse formato rígido, nem a intenção de sê-lo, pois é um documento que tem como propósito servir de parâmetro para a realização do trabalho, onde as necessidades e interesses da escola são elementos considerados essenciais.

O que fica de sugestão, após este estudo, é a reorganização do documento norteador, e a possibilidade de organizar outros documentos, a fim de que as atribuições possam ser estudadas e interpretadas pelos profissionais. Outra questão evidenciada neste estudo refere-se à ausência de formação continuada e de encontros que possibilitem a discussão do cotidiano vivenciado pelos profissionais. 
Para Garrido (2009, p. 10) é importante investir na formação do coordenador já que:

[...] ele é o agente estimulador e articulador desse processo. Para tanto, é preciso que ele, figura isolada em sua unidade escolar, tenha também um espaço coletivo e formador, no qual possa apresentar as dificuldades inerentes à sua nova função, partilhar angústias, refletir sobre sua prática como coordenador, trocar experiências... crescer profissionalmente, para poder exercer de forma plena sua função.

A autora afirma que a reflexão da própria prática propicia o crescimento profissional, essencial para exercer tal função. Os estudos apontam que a função de coordenação pedagógica se organiza a partir de pressupostos teóricos voltados, sobretudo, à articulação do trabalho coletivo. Conceber a inclusão de formação continuada para os profissionais atuantes nessa função é também reconhecer a importância de sua atuação nas escolas.

Ao escutar os sujeitos nesta pesquisa, percebemos que muitos profissionais estabelecem relação de dependência entre as ações cotidianas e as atribuições expostas em documento. Sobretudo, por estarem divididos entre a teoria e a prática, baseados no trabalho fragmentado, não conseguindo, assim, interpretar as ações propostas no documento, que convertem à realização do trabalho coletivo.

Diante do exposto, consideramos a função de assistente técnico-pedagógico, como dito por Garrido (2009), com pouca tradição, e assim como a coordenação pedagógica, em vias de construção (WALTRICK, 2008). Todavia, percebemos grande potencial nesses profissionais, que necessitam edificar sua função nas escolas catarinenses, criando história e tradição, com espaços propícios para discussão da função e de suas ações.

Para que seu trabalho possa pautar-se na mediação e na articulação do trabalho coletivo, apropriando-se dos olhares de constatação e reflexão discutidos por Placco (2010), atendendo a demanda da escola, com interesses e necessidades de toda a comunidade escolar, o assistente técnico-pedagógico precisa sentir-se um elemento a mais, disposto e disponível a contribuir com seus pares para a realização de um trabalho que resulte no sucesso para toda a comunidade escolar.

Recebido em novembro de 2015 e aprovado em abril de 2016

\section{Referências}

AGUIAR, L. G. Desafios do coordenador pedagógico no processo de inclusão de alunos com deficiência no ensino regular. In: ALMEIDA, L. R. ; PLACCO, V. M. N. S. O coordenador pedagógico e o atendimento à diversidade. São Paulo: Edições Loyola, 2010. 
BARCELOS, A. R. F. Supervisão escolar na rede municipal de ensino de Florianópolis: Ascensão, declínio e ressignificação de uma prática. 2014. 215 f. Tese (Doutorado em Educação) - Universidade Federal de Santa Catarina, Florianópolis, 2014.

BARREIRA, K. V. V. Prática em extinção ou processo de renovação? Um estudo sobre a supervisão educacional. 2006. 121 f. Dissertação (Mestrado em educação) - Faculdade de Educação, Universidade Federal de Minas Gerais, Belo Horizonte, 2006.

CORRÊA, S. S. Assistente Técnico-pedagógico: atribuições legais e prática profissional. 2013. 116 f. Dissertação (Mestrado em Educação) - Universidade do Vale do Itajaí, Itajaí, 2013.

GARRIDO, E. Espaço de formação continuada para o professor-coordenador. In: BRUNO, E. et al. (Orgs). $\mathbf{O}$ coordenador pedagógico e a formação docente, 9. ed. São Paulo: Edições Loyola, 2009.

GEGLIO, P. C. O papel do coordenador pedagógico na formação do professor em serviço. In:

PLACCO, V. M. N. S. e ALMEIDA, L. R. O coordenador pedagógico e o cotidiano da escola. 8. ed. São Paulo: Loyola, 2011.

GESSER, V. O Planejamento educacional: da gênese histórico-filosófica aos pressupostos da prática. Curitiba: CRV, 2011.

PLACCO, V. M. N. S. O coordenador pedagógico no confronto com o cotidiano da escola. In: PLACCO, V. M. N. S.; ALMEIDA, L. R. O coordenador pedagógico e o cotidiano da escola. 7. ed. São Paulo: Edições Loyola, 2010.

PLACCO, V. M. N. S. O coordenador pedagógico no confronto com o cotidiano da escola. In: PLACCO, V. M. N. S.; ALMEIDA, L. R. O coordenador pedagógico e o cotidiano da escola. 8. ed. São Paulo: Edições Loyola, 2011.

PIMENTA, S. G. Questões sobre a organização do trabalho na escola. Disponível em www. coordenacaoescolagestores.mec.gov.br/ufsc Acesso em: 22 abr. 2012.

PINTO, U. A. Pedagogia escolar: coordenação pedagógica e gestão educacional. São Paulo: Cortez, 2011.

SAVIANI, D. A supervisão educacional em perspectiva histórica: da função à profissão pela mediação da ideia. In: FERREIRA, N. S. C. (Org.) Supervisão educacional para uma escola de qualidade. 4 ed. São Paulo: Cortez, 2003.

SOARES, A. F. C. Coordenação pedagógica: ações, legislação, gestão e a necessidade de uma educação estética. 2011. 140f. Dissertação (Mestrado em Educação) - Universidade do Vale do Itajaí, Itajaí, 2011.

SOUZA, V. L. T. de. O coordenador pedagógico e a constituição do grupo de professores. In: ALMEIDA, L. R. de; PLACCO, V. M. N. de S. (Org.). O coordenador pedagógico e o espaço da mudança. 9. ed. São Paulo: Edições Loyola, 2011.

VASCONCELLOS, C. dos S. Planejamento: projeto de ensino-aprendizagem e projeto políticopedagógico. 16. ed. São Paulo, SP: Libertad, 2006.

WALTRICH, R. E. de L., O Coordenador pedagógico na educação infantil da rede municipal de educação de Florianópolis: Marcas de uma experiência democrática. 2008, 178 f. Dissertação (Mestrado em Educação) - Universidade Federal de Santa Catarina, Florianópolis, 2008. 